\title{
Comparative Study of Ripe and Unripe Banana Flour during Storage
}

Singham Pragati ${ }^{*}$, Genitha I ${ }^{2}$ and Kumar Ravish ${ }^{2}$

${ }^{1}$ Department of Food Technology, Vignan University, Vadlamudi, Guntur, India

${ }^{2}$ Department of Food Engineering, NIFTEM, Haryana, India

\begin{abstract}
Banana flour is an excellent alternative to minimize postharvest losses and to retain the nutritive value of fresh bananas. Unripe banana flour is rich in resistant starch, dietary fiber, and aids in colon health. Ripe banana flour contains high amount of iron calcium, potassium and reducing sugars which helps in better blood circulation and also aids in curbing the craving for nicotine, caffeine. Comparative effect on physico-chemical, re-constitutional and sensory qualities of prepared unripe and ripe banana pulp flour were evaluated during the storage of sixty days at ambient conditions. Water absorption capacity of unripe banana flour was greater than ripe banana flour. From FTIR spectroscopy it was cleared that ripe banana flour was more dried than unripe banana flour. Due to presence of sugars in ripe banana flour, its hygroscopicity was much higher than unripe banana flour. Potential value added products such as cookies from unripe banana flour and bread from ripe banana flour were prepared to determine the utilization of banana flour as functional food ingredient.
\end{abstract}

Keywords: Unripe banana flour; Ripe banana flour; Physical properties; Rehydration properties

\section{Introduction}

Banana is the second largest produced fruit after citrus, contributing about $16 \%$ of world's total fruit production. India out of 16.81 million metric tonnes annual production of banana [1] over $30 \%$ of the produce is wasted due to postharvest loses [2]. It is a perishable fruit and gets easily spoiled. Banana is favorable for industrial processing due to its rich content of soluble solids, minerals and low acidity. According to the new economic strategy to increase waste utilization of food products and convert them into various innovative products. Banana includes the production of banana flour when the fruit is unripe, and to incorporate the flour into slowly digestible cookies [3], high-fibre bread [4] and edible films [5].

The clear advantage presented by green banana flour includes a high total starch (73.4\%), resistant starch (17.5\%) and dietary fibre content $(\sim 14.5 \%)$. Resistant starch which is the indigestible starch that passes through the small intestine to the large intestine and is fermented in the colon [6]. It can also be defined as "the sum of starch and products of starch degradation not absorbed in the small intestine of healthy individuals". Regular consumption of green banana flour can be expected to confer beneficial health benefits for humans [7]. Among the four subtypes of resistant starch Resistant Starch type II (RS II) (i.e that occurs in natural granular form) is present in green bananas which is involved in disease prevention including modulation of glycemic index, diabetes, cholesterol lowering capability and weight management [8]. It improves digestion health by resisting starch hydrolyzing enzymes in the stomach and thus acts as dietary fibre.

RS II breaks down into short chain fatty acids \& raise the $\mathrm{pH}$ level of large intestine which creates adverse conditions for pathogenic bacteria while favour the growth of beneficial bacteria. Butyrate, one of the short fatty acids inhibits the development of malignant cells which can become cancerous. It increases faecal bulking which promotes colon health [9-12] and also acts as a rehydrating agent for those suffering from diarrhoea [13]. It helps in slow digestion of blood glucose and insulin level. Low insulin level triggers the use of body fat and helps in prevention of type II diabetes and manages obesity [14]. It binds bile acids, cholesterol in digestive system and prevents their absorption from blood stream. Apart from these it also helps in prevention of osteoporosis by increasing the absorption of calcium and other minerals including magnesium iron etc. It also serves as a carrier of probiotics to the large intestine where they can maximize their benefits which include boosting the immune system.

On the other hand, ripe banana flour that is less known banana product, may offer high content of carbohydrate containing high level of sugar, starch and dietary fibre. It has the potential to offer new product from industrial, domestic uses and can be incorporated into food products requiring solubility, sweetness and small quantity of sugar. It is adjuvant in different food preparation and baby food formulation. Other than health and sensory reasons, the stages of ripeness are also important for technical aspect of processing. Banana pulp flour prepared using fruits at different stages of ripening has been shown to behave differently during manufacture of food products such as cakes [15] and extruded products [16]. Being able to differentiate between banana flour prepared from different stages of ripeness could help food processors to control the quality of food incorporated with banana flour.

Therefore Converting banana fruit into flour was found to be an effective preservation method [17]. Comparative characteristics of unripe and ripe banana flour during were still not researched hence this present study was undertaken with following objectives:

- To prepare banana flour from ripe and unripe fruit.

- To compare physico-chemical and flour properties of ripe and unripe banana flour during storage period

- To prepare two food products from prepared banana flour.

\section{Materials and Methods}

\section{Materials}

Fresh good quality banana of Cavendish variety unripe at stage \#1

*Corresonding author: Singham Pragati, Department of Food Process Engineering, SHIATS, Allahabad, India, E-mail: pragati.niftem@gmail.com

Received July 17, 2014; Accepted October 16, 2014; Published October 21 2014

Citation: Pragati S, Genitha I, Ravish K (2014) Comparative Study of Ripe and Unripe Banana Flour during Storage. J Food Process Technol 5: 384. doi: 10.4172/2157-7110.1000384

Copyright: ( 2014 Pragati S, et al. This is an open-access article distributed under the terms of the Creative Commons Attribution License, which permits unrestricted use, distribution, and reproduction in any medium, provided the original author and source are credited. 
and ripe at \#4 were procured from the local market of Allahabad. Care was taken to select firm and mature fruits without any defect on visual inspection and according to ripeness index (Figure 1).

Unripe banana flour was found as light yellow colour: Coloured starchy flour while ripe banana flour was yellowish brown in colour due to caramelization of sugar at $60^{\circ} \mathrm{C}$ as shown in Figure 2. The wastage ratio of peel: pulp was found to be more in case of unripe banana as compared to ripe banana while quantity of flour was greater in ripe banana than unripe banana flour. Triplicates were taken to analyse the flour for physic-chemical, flour characteristics and microbial analysis during the study period of 60 days. Results were taken after 20 days interval.

\section{Physico-Chemical analysis: Determination of moisture}

Moisture content was determined by AOAC, 1990 and was calculated using formula:

Moisture Content $(\%)=\frac{\text { Initial Sample Weight }- \text { Final Sample Weight }}{\text { Initial Weight }} \times 100$

Determination of ash: It was evaluated by Ranganna, 2007 as:

$$
\text { Ash content }(\%)=\frac{\text { Initial Sample Weight }- \text { Final Sample Weight }}{\text { Initial Weight }} \times 100
$$

Determination of fat: It was determined using Soxhlet apparatus

by AOAC, 1990 method and was calculated as:

$$
\text { Fat content }(\%)=\frac{\text { Initial Weight of receiver }- \text { Final Weight of receiver }}{\text { Initial Weight of receiver }} \times 100
$$

\section{Physical characteristics}

Colour analysis: The colour of the samples was measured with a Konica Minolta Chroma CR-200 colori meter. Colour was represented by the Lab presentation method in which ' $\mathrm{L}$ ' is the lightness of the colour, and equals zero for black and 100 for white. The ' $a$ ' is the degree of redness ( 0 to 60$)$ or greenness $(0$ to -60$)$ while ' $b$ ' is the amount of yellowness ( 0 to 60$)$ or blueness ( 0 to -60$)$. Five replicates, each consisting of an average of five measurements were made to obtain an overall colour for each treatment. Quantitative evaluations were made by examining the total colour change.

Water activity: Water activity of Tray dried unripe and ripe banana flour was measured using Aqualab 4TE dew point water activity meter (Decagon, USA). It is based on chilled mirror technique. It measures the vapour pressure using the dew point temperature, which directly gives the water activity.

Bulk density: It is the ratio of the mass of the particle to the volume of the particle, excluding open and closed pores. It affects the flowability of the green banana flour.

\section{Porosity}

Particle density/True density/Solid density: Apparent particle density or envelope density is the mass per unit volume of a particle, excluding the open pores but including the closed pores. Gas or liquid displacement methods like gas or liquid pycnometry are adopted for the measurement of apparent particle density. A $2.5 \pm 0.04 \mathrm{~g}$ of each of tray dried and vacuum tray dried banana flour $250 \mu \mathrm{m}$ was placed in an empty liquid pycnometer $(25 \mathrm{ml})$, and filled with measured volume of toluene. Toluene was used because of its ability to penetrate the finest external pores connected to surface of the material without dissolving the material.

$$
\text { Porosity }=1-\frac{\text { Bulk density }}{\text { Particle density }}
$$

\section{Rehydration characteristics}

Water absorption capacity (WAC): Water absorption capacity was determined using the method with slight modifications. $10 \mathrm{ml}$ of distilled water was added to $1.0 \mathrm{~g}$ of the sample in a beaker. The suspension was stirred using a magnetic stirrer for $5 \mathrm{~min}$. The suspension obtained was thereafter centrifuged at $3555 \mathrm{rpm}$ for 30 min and the supernatant measured in a $10 \mathrm{~mL}$ graduated cylinder. The density of water was taken as $1.0 \mathrm{~g} / \mathrm{cm}^{3}$. Water absorbed was calculated as the difference between the initial volume of water added to the sample $\left(\mathrm{W}_{1}\right)$ and the volume of the supernatant $\left(\mathrm{W}_{2}\right)$.

$$
\mathrm{WAC}=\mathrm{W}_{1}-\mathrm{W}_{2}
$$

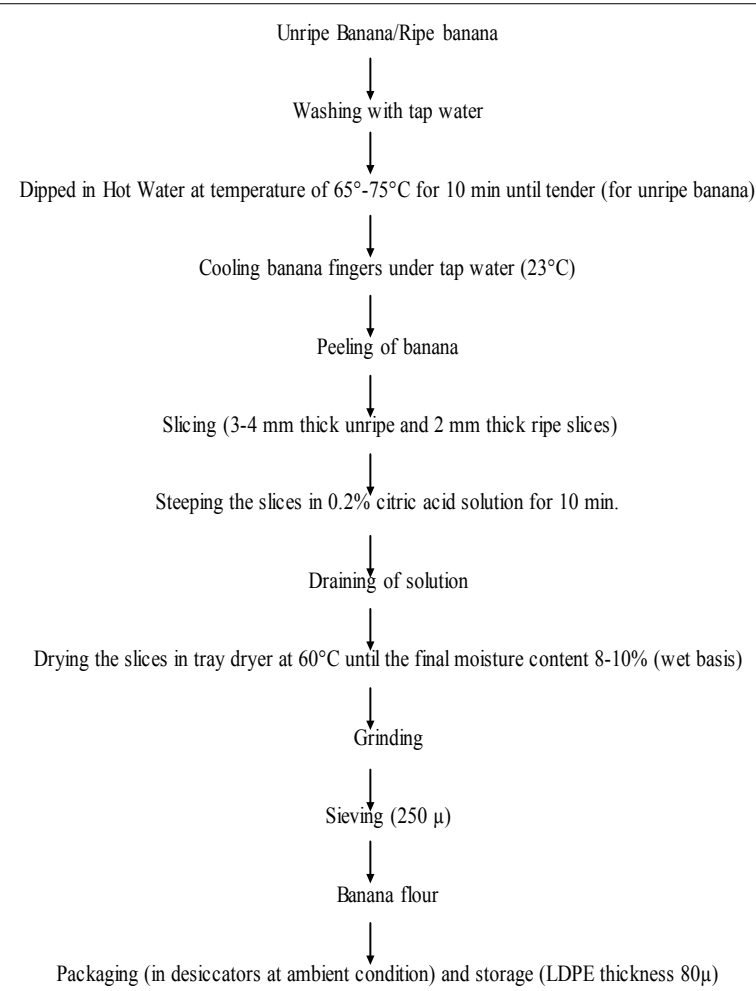

Figure 1: Flow chart for banana flour preparation (Sajilata et al. 2006)
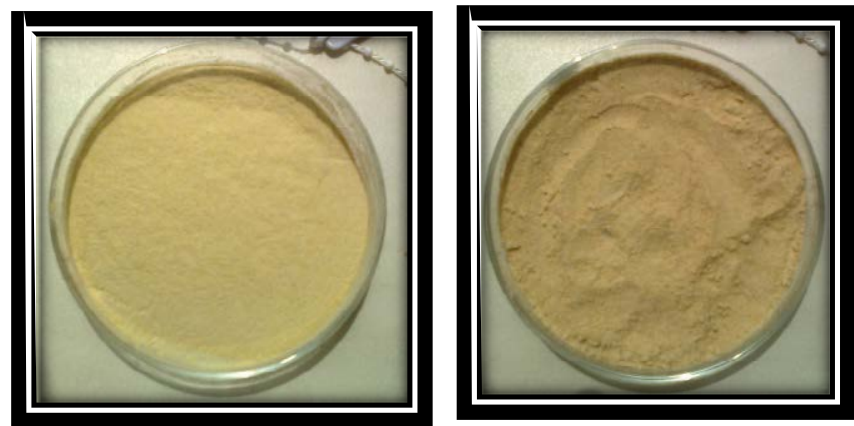

Figure 2: Prepared unripe and ripe banana flour 
Solubility: The supernatant obtained after the WAC (water absorption capacity) is weighed $\left(\mathrm{M}_{1}\right)$ and transferred into a moisture dish. It is then kept into hot air oven at $105^{\circ} \mathrm{C}$ for $4 \mathrm{hrs}$ [18] samples are again put into the hot air oven until constant weight is obtained. After drying immediately samples were transferred into a desiccator to cool. Cooled samples were then weighed $\left(\mathrm{M}_{2}\right)$. The solubility of the powder (\%) was determined by taking the weight difference.

$$
\text { Solubility }=\mathrm{M}_{1}-\mathrm{M}_{2}
$$

Swelling power: Swelling power defines capacity of the particles to hold water and

$$
\mathrm{SP}(\mathrm{g} / \mathrm{g})=\left[\mathrm{W}_{3} /\left(\mathrm{W}_{1} \times(100-\text { Solubility })\right)\right] \times 100
$$

SP is the swelling power of the flour sample (in $\mathrm{g} / \mathrm{g}$ ) $\mathrm{W}_{1}$ is the weight of flour sample (in $\mathrm{g}$ ), $\mathrm{W}_{2}$ is the dried weight of supernatant (g) and $\mathrm{W}_{3}$ is the weight of sediment paste (in $\mathrm{g}$ ).

Differential Scanning Calorimetry (DSC): The temperature and enthalpy of gelatinization of the starches were studied using a Differential Scanning Calorimeter DSC Model No. DSC 200 F3 Maia (NETZSCH- Gerätebau GmbH). The samples were weighed (between 9 and $11 \mathrm{mg}$ sample, dry basis) in aluminium pans, adding distilled water to create excess water conditions in the ration of 1:2. The pans were hermetically sealed, pierced and placed at a centre of the sample holder. An empty pan was used as reference. The samples were heated from baseline of 25 to $180^{\circ} \mathrm{C}$ at a heating rate of $10 \mathrm{~K} / \mathrm{min}$. Liquid nitrogen was purged at the flow rate of $20 \mathrm{ml} / \mathrm{min}$ with a pressure of 0.5 Kpa. The gelatinization or peak temperature $(\mathrm{Tg})$ i.e the glass transition temperature $(\mathrm{Tg})$ or we can say the temperature at which the glassy state of starch changing into rubbery state. Area covered by the peak was calculated as the transition enthalpy $(\Delta \mathrm{H})$ onset and end of the peak was also calculated to define the range of the peak. All calculations were obtained directly by using the accompanying Proteus software. Duplicate measurements were carried out.

Fourier Transform Infrared (FTIR) spectroscopy: The mid-infrared spectra were collected using a Bruker ALPHA infrared spectrometer (Bruker, U.K.) equipped with a DTGS detector and a heated single reflectance ATR cell with a ZnSe (Zinc Selenide) crystal. Due to this crystal it has limitations that it can measure the sample only below $\mathrm{pH} 8$ and above $\mathrm{pH} 5$ i.e samples near to neutral $\mathrm{pH}$ can be measured accurately. For each spectrum, 24 scans were acquired at a resolution of $4 \mathrm{~cm}-1$ and co-added. All sample measurements were recorded at a temperature of $25^{\circ} \mathrm{C}$. Wavenumber range selected for unripe and ripe banana flour was $600-4000 \mathrm{~cm}^{-1}$. Interferogram size was 15038 and spectrum was acquired using the standard direct mode where the background was recorded with no sample in the ATR cell. Data analysis was carried out using the OPUS 7.2 software (Bruker, U.K.).

\section{Microbial analysis}

Total Plate Count (TPC): The sample $(1 \mathrm{ml})$ from dilution blank was poured in sterile petri plate in sterile conditions in triplicate leaving one control plate. Liquified Trypton Yeast extract, Glucose Agar (TyGA) at 42 to $44^{\circ} \mathrm{C}$ introduced 12 to $15 \mathrm{ml}$ in each plate by rotating and tilting the dish mixture was spread evenly over the bottom of plate. After solidification of media the plates were inverted and promptly placed in the incubator at $37^{\circ} \mathrm{C}$ for 24 to 48 hours. After 48 hours incubation, all colonies on selected plates were counted. For numerical estimation, colonies per plate were multiplied by proper dilution factor and the results recorded as plate count per millilitre or plate count per gram ( $\mathrm{pc} / \mathrm{ml}$ or $\mathrm{pc} / \mathrm{g})$.
Sensory analysis of finished products: The organoleptic qualities of ripe and unripe banana flour were determined by 9-point hedonic scale. Sensory attributes includes colour, aroma, taste and overall acceptability of banana flour products were evaluated. Cookies from ripe banana flour and bread from unripe banana flour was prepared for sensory evaluation by 5 expert judges (Figure $3 a$ and $3 b$ ).

\section{Results and Discussion}

\section{Effect on proximate properties}

Gradual increase in moisture content of ripe and unripe banana flour was observed during storage period. This was due to hygroscopic nature of the flour to absorb moisture from the surrounding environment though the packaging material. Ripe banana flour absorbed more moisture as compared to unripe banana flour. It is due to the reason because UBF contains high amount of starch which has crystalline structure containing amylase (1,4 a glycosidic linkage) \& amylopectin (branched structure 1-4 a glycosidic linkage) and does not readily participate in hydrogen bonding with water molecules while ripe banana flour possess aldoses and ketoses of monosaccharide or oligosaccharide which are oxidised by moisture and form hydrogen bonds. Maximum moisture obtained by ripe and unripe banana flour was 11.02 and 11.18 respectively, which is below recommended value of fruit powders (13\%) and is stable from microbial deterioration [19].

Ash content depends on the quality of flour and thus corresponds to the higher mineral content, especially sodium $(76.64 \pm 30.0 \mathrm{mg} / 100$ gm flour) and magnesium (98.30 $\pm 5.2 \mathrm{mg} / 100 \mathrm{~g}$ flour) in Cavendish variety [20]. Banana flour is the richest source of potassium $679.71 \pm$ $81.2 \mathrm{mg} / 100 \mathrm{gm}$ flour. Mineral content of UBF and RBF was increased due to leaching of minerals during storage period. Moisture also supported the leaching process in banana flour. Increasing trend of ash content is shown in Figure 3

Fat content of the UBF and RBF decreased with increase in moisture shown in Figure 4, while no change was observed in flavour of the flour i.e oxidative rancidity was not triggered. Fat content of UBF and RBF was decreased 0.37 and 0.92 respectively (Table 1 ).

\section{Effect on physical properties of flour}

Color: Initially UBF was faded yellowish with little tinge of greenness while RBF was darker in colour. RBF was of mixture slightly red and slight yellow. After storage period colour of UBF increased as yellowish green with some amount of darkness. RBF became darker with increase in redness and decrease in yellowness (Table 2).

Water activity: Water activity of the UBF as well RBF increased with time due to hygroscopic nature of flours. Hygroscopicity is due to the attainment of equilibrium between product and surrounding environment at particular relative humidity and temperature conditions. Due to increase in water activity bulk density of the flours also increased. Bulk density relates with the flowability of the flour therefore it can affect the conveying and storage properties (Table 3).

Effect on rehydration characteristics: Water absorption capacity of the flours also decreased due to increase in moisture content i.e moisture uptake decreased due to establishment of equilibrium moisture content of the flour during storage period of 60 days. Starch (polysachharides) present in UBF was more able to bind water as gelatinization of starch took place. Likewise WAC ability to bind more number water by polysaccharides as well as monosaccharide present in $\mathrm{UBF}$ and $\mathrm{RBF}$ also decreases resulting in decreased solubility of the flour. 


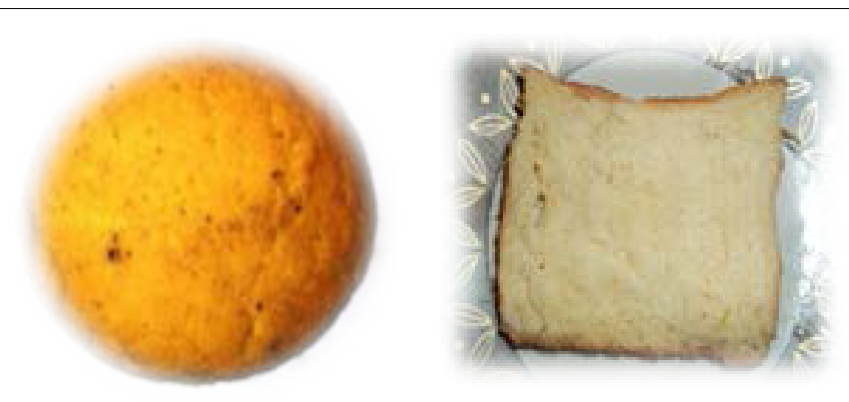

Figure 3: (a) Cookie prepared from unripe banana flour (b) Bread prepared from ripe banana flour

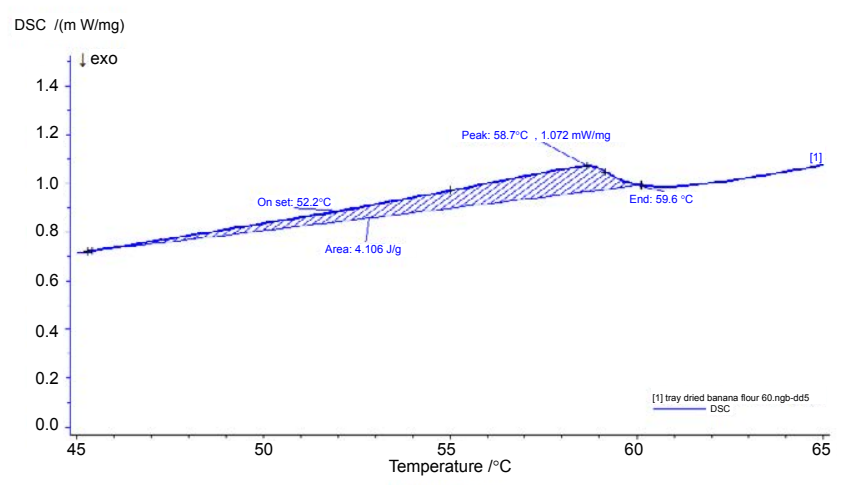

Figure 4: DSC plot of unripe banana flour

\begin{tabular}{|c|c|c|c|c|c|c|}
\hline \multirow[t]{2}{*}{ Days } & \multicolumn{2}{|c|}{ Moisture content (\% w.b) } & \multicolumn{2}{|c|}{ Ash Content (\%) } & \multicolumn{2}{|c|}{ Fat Content (\%) } \\
\hline & $\mathrm{UBF}^{*}$ & RBF* $^{*}$ & UBF* & RBF* $^{*}$ & UBF$^{*}$ & RBF* $^{*}$ \\
\hline 0 & 8.9 & 9.11 & 3.52 & 4.22 & 0.5 & 1.19 \\
\hline 20 & 9.43 & 9.69 & 3.58 & 4.55 & 0.44 & 1.09 \\
\hline 40 & 10.19 & 10.28 & 3.67 & 4.67 & 0.4 & 1.01 \\
\hline 60 & 11.02 & 11.18 & 3.75 & 4.8 & 0.37 & 0.92 \\
\hline
\end{tabular}

$\mathrm{UBF}^{*}=$ Unripe Banana Flour; RBF*=Ripe Banana Flour

Table 1: Proximate analysis of unripe and ripe banana flour

\begin{tabular}{|c|c|c|c|c|}
\hline & \multicolumn{2}{|c|}{ UBF* } & \multicolumn{2}{c|}{ RBF* $^{*}$} \\
\hline & Initial & Final & Initial & Final \\
\hline L & 81.315 & 80.624 & 72.43 & 70.64 \\
\hline a & -0.468 & -0.51 & 3.27 & 4.82 \\
\hline b & 19.023 & 20.472 & 19.314 & 17.867 \\
\hline
\end{tabular}

$\mathrm{UBF}^{*}=$ Unripe Banana Flour; RBF*=Ripe Banana Flour

Table 2: Colour analysis unripe and ripe banana flour

\begin{tabular}{|c|c|c|c|c|}
\hline & \multicolumn{2}{|c|}{ Initial } & \multicolumn{2}{c|}{ After 60 days } \\
\hline & UBF & RBF & UBF & RBF \\
\hline Water activity & 0.21 & 0.22 & 0.44 & 0.50 \\
\hline Bulk density & 0.67 & 0.72 & 0.65 & 0.70 \\
\hline Porosity & 0.19 & 0.13 & 0.21 & 0.15 \\
\hline
\end{tabular}

$\mathrm{UBF}^{*}=$ Unripe Banana Flour; RBF*=Ripe Banana Flour

Table 3: Effect on physical properties of unripe and ripe banana flour

\begin{tabular}{|l|c|c|c|c|}
\hline & \multicolumn{2}{|c|}{ Initial } & \multicolumn{2}{c|}{ After 60 days } \\
\hline & UBF$^{*}$ & RBF $^{*}$ & UBF$^{*}$ & RBF$^{*}$ \\
\hline Water absorption capacity (WAC) (ml) & 5.7 & 3.5 & 5.0 & 3 \\
\hline Solubility & 0.99 & 0.901 & 0.957 & 0.863 \\
\hline Swelling power (\%) & 3.57 & 2.93 & 3.53 & 2.02 \\
\hline
\end{tabular}

$\mathrm{UBF}^{*}=$ Unripe Banana Flour; $\mathrm{RBF}^{*}=$ Ripe Banana Flour

Table 4: Effect on rehydration characteristics of ripe and unripe banana flour

Solubility affects the swelling power of the banana flour. Its percentage decreased during course of storage because flour particulates have already imbibes the water molecules from the surroundings (Table 4).

Effect on gelatinization temperature: Unripe Banana flour had a gelatinisation peak temperature $(\mathrm{Tg})$ of $58.7^{\circ} \mathrm{C}$ with a gelatinisation enthalpy $(\Delta \mathrm{H})$ of $4.106 \mathrm{~J} / \mathrm{g}$ while ripe banana flour had $\mathrm{Tg} 45.1$ with $\Delta \mathrm{H}$ $7.915 \mathrm{~J} / \mathrm{g}$. As the banana starch showed a mixture of the A- and B-type crystal polymorphs, this could indicate that it had a long average chain length. This high gelatinisation temperature is in agreement with the X-ray diffraction pattern (A/B-type) showed, since the level of crystallinity and in consequence the diffraction pattern, is attributed to the chain length of the amylopectin molecule [21] (Figure 4).

Fourier Transform Infrared (FTIR) spectroscopy: Superimposed FTIR spectra of unripe and ripe banana flour are shown in Figure 5. The information obtained from this technique is related to the shortrange order in the starch molecule [22]. Information on the quantity of ordered and amorphous regions present in the starches is important for knowing the behaviour of the polysaccharide when it is processed, e.g. heat treatments, or to predict the characteristics of the starchy products when they are stored. Before $3500 \mu \mathrm{m}$ wavelength moisture removal took place. Deep O-H shift was obtained in ripe banana flour which indicated that drying of ripe banana was much better than unripe banana flour. Sharp shift also indicates that intra-molecular were more strong in ripe banana flour. Sugars present in RBF holds water molecule in large number and more tightly than starch molecules of UBF. Around $2500 \mu \mathrm{m}$ wavelength atmospheric carbon dioxide was found more prominent in unripe banana flour. Approximately at $1500 \mu \mathrm{m}$ wavelength $\mathrm{C}=\mathrm{O}$ stretching is found more prominent in ripe banana flour as it contains more number of monosaccharides which can lose their carboxyl group easily (Figure 6).

Effect on microbial count: Microbial population of UBF and RBF increased with increase in storage period. It shows that ripe banana flour is more prone to microbial infections as it contains sugars. Total plate Count (TPC) of UBF and RBF was upto $23333 \mathrm{CFU} / \mathrm{ml}$ and 30333 $\mathrm{CFU} / \mathrm{ml}$ respectively in the storage period of 60 days. Minimum TPC for microbial deterioration is 50,000 CFU/ml therefore the flours were microbiologically safe upto the storage period of 60 days in HDPE package at ambient conditions [23-25].

Effect on sensory properties: Sensory properties of banana flour were evaluated at each interval and significant decrease $(\mathrm{p}<0.05)$ was observed in aroma of UBF and RBF due to various deteriorative reaction such as accumulation of moisture, lipid oxidation, leaching of minerals and increase in TPC (Total Plate count) during storage. Sensory evaluation of products, bread from RBF and cookies from UBF is shown in Figure 7 was performed after 60 days of storage on 9-point hedonic scale to discover its utility and palatability which were found to be rich in nutrition as well as taste. The structurability of the cookies 


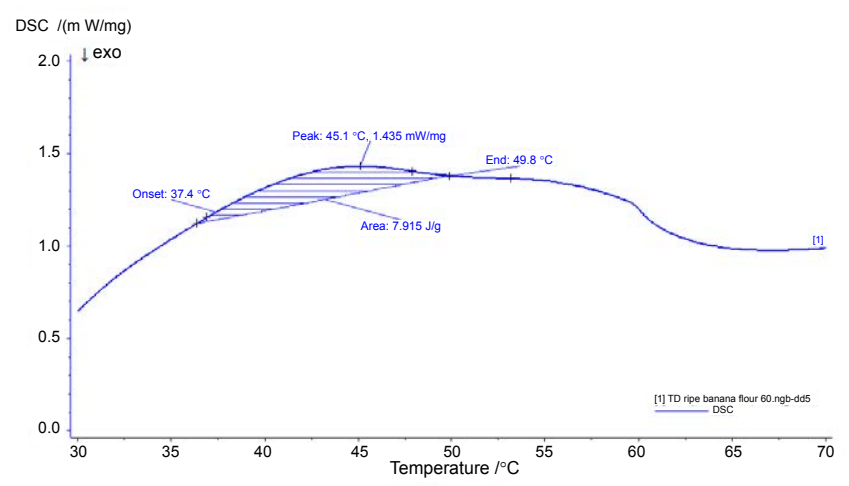

Figure 5: DSC plot of ripe banana flour

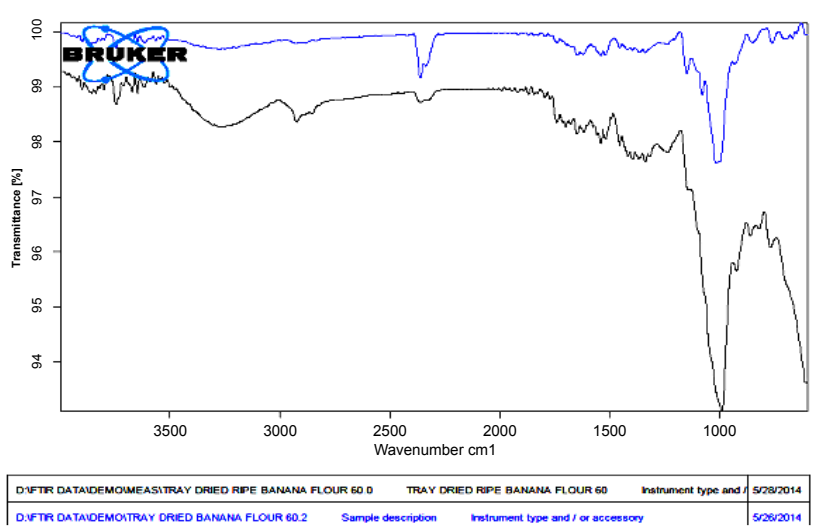

Figure 6: FTIR spectra of unripe banana flour and ripe banana flour

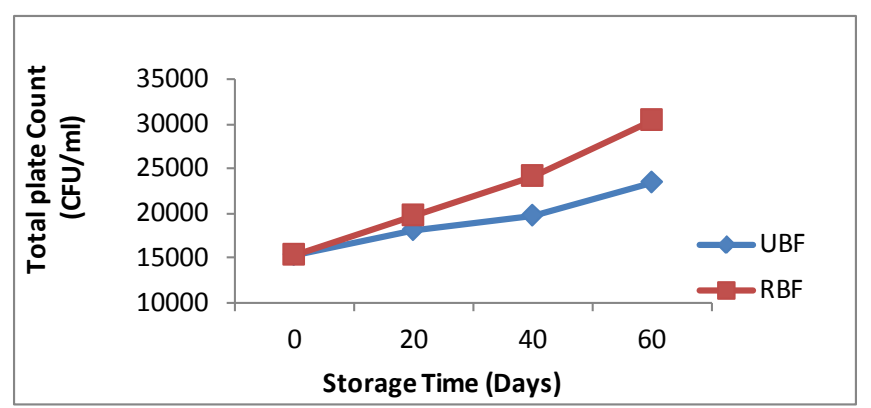

Figure 7: Total Plate count (CFU/ml) of UBF and RBF

of UBF and elasticity of the bread of RBF was reduced due to absence of high amount of gluten and presence of fibres in RBF and UBF respectively. This problem was somewhat overpowered by addition of rich amount of shortners in cookies and refined wheat flour in bread.

\section{Conclusion}

It can be concluded from this study that UBF is excellent source of resistant starch and RBF is good source of soluble carbohydrates. The flours are able to improve the nutritional content of the product by various aspects. Cereal fours blended with banana flour will enhance the acceptability of product on the basis of colour, aroma, appearance; taste etc. Unripe banana possess high starch content hence flour remained free flowing while of ripe banana became lumpy due to presence of high amount of sugars during storage. Storage conditions and maturity of fruit were found to be the most pronounced factors affecting the physicochemical and sensory quality attributes of banana flour. Result obtained that unripe banana flour due to lower moisture content was more preferable than ripe banana flour in LDPE package storage at ambient conditions. The data obtained in this study will be successfully used to predict the shelf life of ripe and unripe banana flour and understand their neutraceutical properties.

\section{References:}

1. Singh HP, Uma S (1996) Genetic diversity of banana in India. In: Proceedings of the Conference on â€œChallenges for Banana Production and Utilization in 21st Century, Trichy.

2. Surendrnathan KK (2005) Post harvest biotechnology of fruits with special reference to banana perspective and scope. BARC, Mumbai. Indian journal of Biotechnology 4: 39-46.

3. Aparicio SA, Sayago ASG, Vargas TA, Juscelino T, Ascencio OTE, et al (2007) Slowly digestible cookies prepared from resistant starch-rich lintnerized banana starch. Journal of Food Composition and Analysis 20: 175-181.

4. Juarez GE, Agama AE, Sayago ASG, Rodriguez ASL, Bello PLA (2006) Composition, digestibility and application in bread making of banana flour. Plant Foods for Human Nutrition 61: 131-137.

5. Rungsinee S, Natcharee P (2007) Oxygen permeability and mechanical properties of banana films. Food Research International 40: 365-370.

6. Fu L, Tian JC, Sun CL, Li C (2008) RVA and farinograph properties study on blends of resistant starch and wheat starch. Agricultural Sciences in China 7 812-822.

7. Roda AAA, Hernandez IA, Agama AJJ, Tovar JE, Bello PLA (2008) Characterization of a fiber-rich powder prepared by liquefaction of unripe banana flour. Food Chemistry 107: 1515-1521.

8. Thakorlal J, Perera CO, Smith B, Englberger L, Lorens A (2010) Resistant starch in Micronesian banana cultivars offers health benefits. Pac Health Dialog 16: 49-59.

9. Brown IL (2004) Applications and uses of resistant starch. J AOAC Int 87: 727 732.

10. Fuentes ZE, Riquelme NMJ, Sanchez ZE, Perez AJA (2010) Resistant starch as a functional ingredient: A review. Food Research International 43: 931-942.

11. Topping D, Bajka B, Clarke J, Cobiac L, Conlon M, et al. (2008) Resistant starches as a vehicle for delievering health benefits to the large human bowel. Microbial Ecology in Health and Diseases 20:103-108.

12. Sharma A, Baljeet S, Ritka (2008) Resistant starch: Physiological roles and food applications. Food Review International 24: 193-234.

13. Raghupathy P, Ramakrishna BS, Oommen SP, Ahmed MS, Priyaa G, et al. (2006) Amylase-resistant starch as adjunct to oral rehydration therapy in children with diarrhea. J Pediatr Gastroenterol Nutr 42: 362-368.

14. Penn-Marshall M, Holtzman GI, Barbeau WE (2010) African americans may have to consume more than 12 grams a day of resistant starch to lower their risk for type 2 diabetes. J Med Food 13: 999-1004.

15. Yomeni MO, Njoukam J, Tchango TJ (2004) Influence of the stage of ripeness of plaintains and some cooking bananas on the sensory and physicochemical characteristics of processed products. Journal of the Science of Food and Agriculture 84: 1069-1077.

16. Gamlath S (2008) Impact of ripening stages of banana flour on the quality of extruded products. International Journal of Food Science and Technology 43 1541-1548.

17. Muzanila YC, Mwakiposa V (2003) Assessment of nutritional status of traditionally prepared banana flour Khenyangwa African Crop Science Conference Proceedings, Sokoine University of Agriculture 6: 564-567.

18. AOAC (1990) Official methods of analysis (15thedn). Washington DC Association of Official Analytical Chemists. 
Citation: Pragati S, Genitha I, Ravish K (2014) Comparative Study of Ripe and Unripe Banana Flour during Storage. J Food Process Technol 5: 384. doi:10.4172/2157-7110.1000384

Page 6 of 6

19. Potter NN, Hotchkiss (1995) Food science (5thedn). Chapman and Hall, Inc., New York.

20. Mcance RA, Widdowson EM (2002) The composition of foods 6th summaried. The Royal Society of chemistry and Food Standards Agency, London.

21. Hizukuri S (1985) Relationship between the distribution of the chain length of amylopectin and the crystalline structure of starch granules. Carbohydrate Research 141: 295-306.

22. Sevenou O, Hill SE, Farhat IA, Mitchell JR (2002) Organisation of the external region of the starch granule as determined by infrared spectroscopy. Int J Biol Macromol 31: 79-85.
23. Ramli SB, Alkarkhi AF, Yong YS, Easa AM (2009) The use of principle component and cluster analyses to differentiate banana pulp flours based on starch and dietary fiber components. Int J Food Sci Nutr 60 Suppl 4: 317-325.

24. Saljilata MG, Singhal RS, Kulkarni PR (2006) Resistant starch A review. Rev Food Sci 5: I-16.

25. Sathe SK, Salunkhe DK (1981) Functional properties of great northern bean (Phaseolus vulgaris) proteins: Emulsion, foaming, viscosity and gelation properties. J Food Sci 46: 71-75. 